\title{
Os desafios do itinerário: em torno de Murilo Mendes
}

Adilson Citelli

Professor titular do Departamento de Comunicações e Artes da ECA/USP, onde ministra cursos de graduação e pós-graduação. Orienta dissertações e teses nas áreas de Comunicação e Linguagem, com ênfase nas subáreas Comunicação/Educação. É coeditor da revista Comunicação E̊ Educação. Pesquisador $1 C$ do CNPq. Autor de inúmeros artigos e livros, dentre os quais se destacam: Linguagem e persuasão (Ática, 1994), Comunicação e educação: a linguagem em movimento (Senac: 2000), Palavras, meios de comunicação e educação (Cortez: 2008).

E-mail: citelli@uol.com.br

Nascido em Juiz de Fora, em 13 de maio de 1901, Murilo Monteiro Mendes morreu em Lisboa no dia 13 de agosto de 1975. Iniciou cursos superiores de Farmácia e depois Direito sem chegar a concluí-los. Em 1920 mudou-se para o Rio de Janeiro. Teve vida profissional instável, com empregos díspares: prático de dentista, professor de francês, funcionário de cartório, telegrafista, arquivista do Ministério da Fazenda, escriturário de banco, Inspetor Federal de Ensino. Nos primeiros anos da década de 1920 iniciou colaboração para jornais e publicações de recorte Modernista, como a Revista de Antropofagia e Terra Roxa e Outras Terras. A partir de 1953 passou a viver a maior parte do tempo na Europa, fixando-se em Roma no ano de 1957. Na Itália foi professor de Cultura e Literatura Brasileira, ministrando aulas na Universidade de Roma e de Pisa.

Os seus livros iniciais, Poemas (1930), História do Brasil (1932) e Bumba-Meu-Poeta, escrito em 1930, mas publicado em 1959, na edição da obra completa intitulada Poesias (1925-1955), revelam o seu diálogo com o modernismo e as vanguardas europeias, conquanto fortemente implicados com as questões brasileiras e mesmo mineiras. Deste período irrompem poemas de tom irônico, sarcásticos, com linguagem provocativa, a exemplo dos dois textos a seguir:

\footnotetext{
1. GUIMARÃES, Júlio Castañon e MOURA, Murilo Marcondes de (Orgs.). Antologia poética. Murilo Mendes. São Paulo: Cosac Naify, 2014, p. 8.

2. Idem. p. 12.
} 


\section{Canção do exílio ${ }^{l}$}

Minha terra tem macieiras da Califórnia

onde cantam gaturamos de Veneza.

Os poetas da minha terra

são pretos que vivem em torres de ametista,

os sargentos do exército são monistas, cubistas,

os filósofos são polacos vendendo a prestações.

A gente não pode dormir

com os oradores $e$ os pernilongos.

Os sururus em família têm por testemunha a Gioconda.

Eu morro sufocado

em terra estrangeira.

Nossas flores são mais bonitas

nossas frutas mais gostosas

mas custam cem mil réis a dúzia.

Ai quem me dera chupar uma carambola de verdade

e ouvir um sabiá com certidão de idade!

No texto, o eu poético adota procedimento em ritmo de piada tendo por alvo certa visão ufanista do Brasil e institui um jogo paródico com a Canção do Exílio, de Gonçalves Dias, à maneira do que fizeram ou fariam Oswald de Andrade (Canto de regresso à pátria), Carlos Drummond de Andrade (Nova canção do exílio), Affonso Romano Sant’Anna (A canção do exílio mais recente), e tantos outros poetas e prosadores.

Família Russa no Brasil

O Soviete deu nisto,

seu Naum largou de Odessa numa chispada, abriu vendinha em Botafogo,

logo no bairro chique.

Veio com a mulher e duas filhas, uma delas é boa posta de carne, a outra é garotinha mas promete.

No fim de um ano seu Naum progrediu, já sabe que tem Rui Barbosa, Mangue, Lampião.

Joga no bicho todo o dia, está ajuntando pro carnaval,

3. Idem. p. 91.

4. Bosi, Alfredo. História concisa da literatura brasileira. São Paulo: Cultrix, 1972, p. 500.
As filhas dele instalaram-se na vida nacional.

Sabem dançar o maxixe conversam com os sargentos em bom brasileiro. 
Chega de tarde a aguardente acabou,

Os fregueses somem, seu Naum cai na moleza.

Nos sábados todo janota ele vai pro criouléu.

Seu Naum inda é capaz de chegar a senador.

O tom sarcástico dedica-se, agora, a mostrar a curiosa adaptação em solo carioca de um imigrado da Rússia revolucionária, que ao enfurnar-se nos trópicos parece abandonar não apenas a rigidez dos Sovietes, como também entregar-se às circunstâncias envolvidas com novos valores e comportamentos, às vezes, pouco ortodoxos da vida brasileira.

Nos anos em torno da segunda guerra mundial, Murilo Mendes produziu um conjunto de poemas de forte marca política, postos nos livros Metamorfose, Mundo enigma e Poesia Liberdade. Do primeiro reproduzimos o poema a seguir:

$1941^{3}$

Adeus ilustre Europa

Os poemas de Donne, as sonatas de Scarlatti

Agitam os braços pedindo socorro:

Chegam os bárbaros de motocicleta,

Matando as fontes em que todos nós bebemos.

Somos agora homens subterrâneos,

Andamos de muletas

Preparadas pelos nossos pais.

$O$ ar puro e a inocência

Estão mais recuados do que os deuses gregos.

Somos o pó do pó,

Fantasmas gerados pelos próprios filhos.

Nunca mais voltará a fé aos nossos corações.

Adeus ilustre Europa.

A conversão de Murilo Mendes, em 1934, ao catolicismo levou à produção, a partir do livro Tempo e eternidade - escrito junto com Jorge de Lima - de textos ocupados em retomar a "poesia de Cristo". Parte significativa da obra do poeta está constituída em torno dos diálogos com as Sagradas Escrituras, a simbologia religiosa, as questões da transcendência do homem. É o que se lê em:

O profeta

A Virgem deverá gerar o Filho

Que é seu Pai desde toda a eternidade.

A sombra de Deus se alastrará pelas eras futuras.

5. MOURA, Murilo Marcondes de. Posfácio. As passagens do poeta. In. Antologia. Murilo Mendes. Op. cit. p. 493. 6. Bosi, Alfredo. Op.cit. p. 498 
comunicação \& educação • Ano XX • número 1 • jan/jun 2015

O homem caminhará guiado por uma estrela de fogo.

Haverá música para o pobre e açoites para o rico.

Os poetas celebrarão suas relações com o Eterno.

Muitos mecânicos sentirão nostalgia do Egito.

A serpente de asas será desterrada da lua.

A última mulher será igual a Eva.

E o Julgador, arrastando na sua marcha as constelações,

Reverterá todas as coisas ao seu princípio.

Na obra poética de Murilo Mendes este percurso espiritual nunca se alia, contudo, a uma inflexão catequética ou publicista da variável religiosa, ganhando extensão nos elementos estéticos renovadores, para os quais acorrem as diversas possibilidades construtivas do poema.

As experiências poéticas de Murilo Mendes, tanto no plano formal como de temas e conteúdos, alcançam amplitude nos registros provocadores que se desdobram em diálogos com o cubismo, os procedimentos futuristas de montagem e mesmo os exercícios com elementos oníricos explorados à larga pelo surrealismo. Ainda em seus últimos poemas escritos nos anos 1970 e parte recolhido no livro Convergência se pode identificar o aprofundamento do diálogo com as vanguardas e com o concretismo. Acerca destas poéticas em cruzamentos, Murilo Marcondes de Moura observa:

"Há em Murilo Mendes um motivo permanente, capaz de abranger as direções principais de sua poesia ao longo da trajetória heterogênea. Ele guarda consigo uma inquietação difícil de ser apaziguada, apresentando ao contrário um movimento contínuo, uma espécie de busca sem termo, de que mesmo o horizonte utópico-religioso do poeta mal pode aliviar a ânsia. Trata-se do motivo da passagem. Ele se manifesta em níveis diversos: existencial, religioso e estético" ${ }^{\circ}$.

Vale dizer, estamos diante de um autor complexo, que busca aliar às temáticas do seu tempo político, humano, existencial, religioso, a exatidão expressiva que não se furta à experimentação poética, ao diálogo com as vanguardas, ao enfrentamento dos desafios intertextuais com as diferentes artes. $\mathrm{Ou}$, como escreve Alfredo Bosi:

Murilo é o poeta de aderência ao ser, poeta cósmico e social que aceita a fruição dos valores primordiais. Tendo mantido firme a sua ânsia libertária, ânsia que partilhou com o Modernismo anterior a 30, jamais cai em formas antiquadas de apologética. Místico, ele perfura a crosta das instituições e dos costumes culturais para morder o cerne da linguagem religiosa, que é sempre ligação do homem com a totalidade. Esse o sentido geral de sua obra, a que só escapa o ciclo de poemas humorísticos anteriores a 30, que fazem o giro piadístico de um Brasil morno e provinciano e ecoam a maneira inicial de Mário e Oswald de Andrade ${ }^{6}$. 


\section{BIBLIOGRAFIA PARCIAL DE MURILO MENDES}

Poemas (1930), Bumba-meu-poeta (1930), História do Brasil (1933), Tempo e eternidade - em parceria com Jorge de Lima (1935), O sinal de Deus (1936), A poesia em pânico (1937), O Visionário (1941), As metamorfoses (1944), Mundo enigma (1945), O discípulo de Emaús (1945), Poesia liberdade (1947), Janelas do caos (1949), Contemplação de Ouro Preto (1954), A idade do serrote (1968), Convergência (1970), Retratos relâmpago (1973).

\section{REFERÊNCIAS}

BOSI, Alfredo. História concisa da literatura brasileira. São Paulo: Cultrix, 1972, p. 500.

MARCONDES DE MOURA, Murilo. Posfácio. As passagens do poeta. In: Antologia. Murilo Mendes. São Paulo: Cosac Naify, 2014.

MENDES, Murilo. GUIMARÃES, Júlio Castañon e MOURA, Murilo Marcondes de, (Orgs.). Antologia poética. Murilo Mendes. São Paulo; Cosac Naify, 2014. 